\title{
Storage design using Fast moving, Slow moving and Non moving (FSN) analysis
}

\author{
Mangara M Tambunan ${ }^{1 *}$, Khalida Syahputri ${ }^{1}$, Indah Rizkya ${ }^{1}$, Rahmi M Sari ${ }^{1}$, and Muhammad D Cahyo ${ }^{1}$ \\ ${ }^{1}$ Universitas Sumatera Utara, Department of Industrial Engineering, Faculty of Enginnering, Medan, Indonesia
}

\begin{abstract}
Storage location assignment is related to the problem in warehousing management. The purpose of this paper is to gain storage allocations of goods in a warehouse based on the fast moving, slow moving and non moving (FSN) analysis as the determination of the allocation of storage based on items popularity that is stored in a warehouse. The method used for the research are fast moving, slow moving, non moving (FSN) and dedicated storage. The analysis can be used to determine the location for goods storage will allocated closer to loading area. Goods with fast moving categories allocated close to to loading area, slow moving items allocated next to fast moving items and nonmoving items allocated next to slow moving items which the farthest location from loading area. The concept of dedicated storage also applied to give a specific location for goods storage. The fast moving category items is $11,4 \%$ and requiring $86.31 \mathrm{~m}^{2}$ area. The slow moving category is $47,8 \%$ and requiring $34.86 \mathrm{~m}^{2}$ area. The non moving category is $40,8 \%$ and requiring $50.04 \mathrm{~m}^{2}$ area so that the total area needed is $171.21 \mathrm{~m}^{2}$.
\end{abstract}

\section{Introduction}

The needs of ease to relate each other until the needs of information quickly. PT. XYZ as one telecommunications company in Indonesia in order to expand the range of a continuous service improvement and needs a storage facility to speed up the flow of supply chain.

Markets are not predictable and need to hold stock at various stages within the supply chain [1]. Decisions regarding the amount of inventory that a company should hold and its location within a company's logistics network are crucial in order to meet customer service requirements and expectations [2].

Storage assignment is a key driver of efficiency and aims to reduce the travelling for picking and retrieving activities [3]. The storage assignment policy within a pick area also influences the performance of an order picking system since it determines the product locations and hence influences the travel time of order pickers in the system [4]. So that with applying storage assignment in warehouse management system may will facilitate the handling of goods in warehouse and optimizing the function of the warehouse.

PT. XYZ warehouse has $1800 \mathrm{~m}^{2}$ building area are consisting of a six-room storage. The kind of items that is stored at the warehouse is the new items, thrift items with the condition can still be reused and also thrift with the condition can not be reused and broke items. Each storage room has different storage function i.e. the main storage (storage one) is a storage area for new and thrift, storage 2.5 and 6 is the conditioned room as storage of finance document, storage 3 is stored the broken and the storage 4 is a non-conditions room as storage of nonfinance document.

The company plans to install the shelf in the storage one as much as 40 bays where each bay has 3 levels of slot for each level enough for 2 pallet with $120 \mathrm{~cm}$ length, width $100 \mathrm{~cm}$, maximum height of items for each pallet is $165 \mathrm{~cm}$ and maximum weight that is able to receive each pallet is $1000 \mathrm{~kg}$. So the total available pallet is 240 pallet.

The problem is the condition of the warehouse is currently overload caused by inefficient policy of placement for storing the items who each items stored whereever in available empty location and does not yet have its own storage. The item stored have not been grouped based on frequency of items activities in storage. Rack in the warehouse yet to be fully developed so that unable to accommodate all items. Warehouse management need to improved to maintain the stability other operational activities.

Dedicated storage in which each location is reserved for an assigned product and only that product may be stored there. Because the locations of products do not change, more popular items can be stored in more convenient locations and workers can learn the layout, all of which makes order-picking more efficient [5]. Dedicated method stored based on similarity of the items so that it will make picking activities become more efficient [6].

There are different criteria, such as size, weight, volume, demand, popularity, cost, and distance, among others, may be used to sort and allocate products to their warehouse positions.

\footnotetext{
Corresponding author: arrapul_tambunan@yahoo.com
} 
FSN analysis groups them into three categories as Fast-moving, Slow-moving and Non-moving (dead stock) respectively. Inventory policies and models for the three categories have to be different. While performing this particular analysis the turnover ratio of each item has to be calculated because the items are sorted and analyzed according to the turnover ratio it possesses[7]. With regard to both the popularity and the storage space requirement storing the most popular items closet to the depot in the warehouse [8].

The allocation mechanism follows the principle that the highly demanded products are allocated in slots next to the $\mathrm{I} / \mathrm{O}$ doors in order to reduce the total handling times (especially during the picking activity) [9]. It specifies the number of storage /retrieval operations per unit. It specifies the frequency of retrieval of goods. It is calculated by ratio between number of goods retrieved and number of goods arrived. The front tracks stores the high frequent retrieval or high popularity goods, the subsequent tracks has lesser popularity values [10].

Classification based on Frequency of Issues/Use is F, $\mathrm{S} \& \mathrm{~N}$ stand for fast moving, slow moving and Non moving items. Fast moving items normally range from $10 \%$ to $15 \%$ of all inventory items. Slow moving items normally range from $15 \%$ to $20 \%$ of all inventory items. Non moving items normally constitute $70 \%$ to $75 \%$ of all inventory items[11].

\section{Methodology}

\subsection{Type of research}

Type of this research is decriptive research, the research aims to describe systematically, factual and accurate about the facts and the nature of the object or a specific population [12]. The purpose of this research is to design storage assignment in warehouse.

\subsection{Methods of data collection}

The initial phase of this study was conducted by identifying problem that happens, measure the size and capacity of storage facilities are available in a storage one as an object research. Identify the material handling tools, identify item's specification so that can be determined group of items that can be stored using storage facility in the form of a rack (racking items) or could not be saved using a rack (unracking items). Based on the specification of items's dimensions and item's weight, calculate frequency of activity of all items. Based on monthly data which indicates the presence of reduction or the addition amount so that can be determine 3 category of items namely fast moving, slow moving and non moving based on the their activities. The storage allocation can be designed by category of activity where items with fast moving categories are arranged close to the loading unloading area, then slow moving category allocated after the fast moving items and non moving item allocated after a slow moving items where the non moving storage are the furthest from the unloading area. Standard Operation Procedure
(SOP) is designed for standardisation of work instructions in order to support the design of the storage assignment.

\section{Result and discussion}

\subsection{The result of the identification of item's specification and the calculation of the average number of items}

Indentification of item's specification are 481 different kinds stored in the storage. The data specifications is in the form dimensions and weight. Based on average number of goods in thr storage, the total amount of goods is 30.236 unit which consist of racking and unracking categorize. Number of type of goods and total number goods in the storage based on racking and unracking items can be seen in Tabel 1 .

Table 1. Number of type units based on characteristic.

\begin{tabular}{|c|c|r|}
\hline Characteristic & Types (kg) & Number of Units \\
\hline Racking & 392 & 29,737 \\
\hline Unracking & 89 & 499 \\
\hline Total & $\mathbf{4 8 1}$ & $\mathbf{3 0 , 2 3 6}$ \\
\hline
\end{tabular}

The number of the items based on weight range can be seen in Table 2 .

Table 2. The number of the type of items based on racking and unracking tems.

\begin{tabular}{|c|r|}
\hline Weight Range (kg) & Type of Items (Unit) \\
\hline $0-50$ & 402 \\
\hline $51-100$ & 40 \\
\hline$>100$ & 39 \\
\hline Total & $\mathbf{4 8 1}$ \\
\hline
\end{tabular}

The number of the type items based on item;s dimensions can be seen in Table 3 .

Table 3. The number of the type of items based on item's

\begin{tabular}{|c|c|c|c|}
\hline \multirow{2}{*}{} & $\begin{array}{c}\text { Dimension } \\
\text { (cm) }\end{array}$ & $\begin{array}{c}\text { Type of } \\
\text { Items (Unit) }\end{array}$ & $\begin{array}{c}\text { The Amount of } \\
\text { Types (Unit) }\end{array}$ \\
\hline \multirow{2}{*}{ Lenght } & $>120$ & 58 & \multirow{2}{*}{481} \\
\cline { 2 - 3 } & $\leq 120$ & 423 & \\
\hline \multirow{2}{*}{ Width } & $>100$ & 20 & \multirow{2}{*}{481} \\
\cline { 2 - 3 } & $\leq 100$ & 461 & \multirow{2}{*}{481} \\
\hline \multirow{2}{*}{ Height } & $>165$ & 38 & \\
\cline { 2 - 3 } & $\leq 165$ & 443 & \multicolumn{2}{|c|}{ dimensions. } \\
\hline
\end{tabular}

Based on the calculation started from September 2016 until September 2017 total overall items are stored as much as 30,236 units. There are 2 characteristic for goods storage goods can be stored using the storage facility in the form of a rack (racking items) or not deposited in a rack (unracking items). Based on the calculation of the average number of goods in a warehouse obtained the total items as many as 30.236 unit which are divided into category racking and unracking. Those kinds of goods and the number of the total of goods in a warehouse based on characteristic of goods are racking or unracking can be seen in Table 4 . 
Table 4. The amount of the types of items based on the characteristics.

\begin{tabular}{|c|c|c|}
\hline Characteristics & Types (Unit) & Amount (Unit) \\
\hline Racking & 392 & 29.737 \\
\hline Unracking & 89 & 499 \\
\hline Total & $\mathbf{4 8 1}$ & $\mathbf{3 0 . 2 3 6}$ \\
\hline
\end{tabular}

\subsection{The result of the item's activity calculation}

Goods activity data in proposing the allocation of goods storage, analyzed is needed to group the goods based on its activities that is incoming and outgoing of the storage. Based on calculation, items are coded to 0 activity to 9 activity where the number 0 means no movement of activity and amount to 196 items and number 9 amount to 3 items which the most popular items. The results of the calculation of the items within one year of activity can be seen in Table 5 .

Table 5. Result of activity calculation.

\begin{tabular}{|c|c|}
\hline Amount of Activity & Type of Items (Unit) \\
\hline 0 & 196 \\
\hline 1 & 132 \\
\hline 2 & 65 \\
\hline 3 & 33 \\
\hline 4 & 21 \\
\hline 5 & 12 \\
\hline 6 & 10 \\
\hline 7 & 6 \\
\hline 8 & 6 \\
\hline 9 & 3 \\
\hline Total & $\mathbf{4 8 1}$ \\
\hline
\end{tabular}

The amount of activity then sorted from the smallest to the largest and the overall items are divided into 3 categories as a storage grouping. Fast moving categories is $11.43 \%$, slow moving is $47.82 \%$ and the non moving is $40.75 \%$ from all items. The result of the analysis of item's activities in one year can be seen in Table 6 .

Table 6. The result of the analysis of item's activities.

\begin{tabular}{|c|c|c|c|}
\hline Activities & Categories & Types (Unit) & Pecentage \\
\hline $\mathbf{0}$ & Non Moving & 196 & $40,75 \%$ \\
\hline 1 & \multirow{3}{*}{ Slow Moving } & 132 & \multirow{3}{*}{$47,82 \%$} \\
\hline 2 & & 65 & \\
\hline 3 & & 33 & \\
\hline 4 & \multirow{6}{*}{ Fast Moving } & 21 & \multirow{6}{*}{$11,43 \%$} \\
\hline 5 & & 12 & \\
\hline 6 & & 10 & \\
\hline 7 & & 6 & \\
\hline 8 & & 6 & \\
\hline 9 & & 3 & \\
\hline \multicolumn{2}{|c|}{ Total } & 481 & \\
\hline
\end{tabular}

\subsection{The result of storage allocation}

The design of the storage allocation using FSN analysis for both of groups there is racking items and unracking items. Racking items stored using storage facility in the form of a shelf.

Based on the identification of items specification in a warehouse there are 392 type of items which can be stored on a shelf. However, for items with document type, the company stored in specific document warehouses and for the types of batteries with total more than 100 units not allocated to storage one and stored to stored 3. While for the battery with the amount of less than 100 units allocated to storage one that stored using rack.

So that, from whole racking item that are allocated to storage one only 346 types. The amount and types of racking type can be seen in Table 7 .

Table 7. Amount and types of racking items.

\begin{tabular}{|c|c|c|}
\hline Catogory & Types (Unit) & Amount (Unit) \\
\hline Fast Moving & 37 & 12.031 \\
\hline Slow Moving & 178 & 3.973 \\
\hline Non Moving & 196 & 4.574 \\
\hline Total & $\mathbf{3 4 6}$ & $\mathbf{2 0 . 5 7 8}$ \\
\hline
\end{tabular}

In the Storage one there are area that consists of 10 rows of shelves that are given the symbol with the letters A, B, C, D, E, F, G, H, I and J in which each line there are 4 bays each bay consists of 3 levels of slot and for each slot at every level enough for 2 pallet size lenght $120 \mathrm{~cm}$, width $100 \mathrm{~cm}$ and maximum height of items is $165 \mathrm{~cm}$ and a maximum weight per pallet is $1000 \mathrm{~kg}$, so the total overall pallet is 240 pallet. The result of storage allocation of racking items can be seen in Table 8 and Table 9.

Table 8. Storage allocation of racking items.

\begin{tabular}{|c|c|c|c|}
\hline Rack & Pallet Available & $\begin{array}{c}\text { Used } \\
\text { Pallet }\end{array}$ & $\begin{array}{c}\text { Types } \\
\text { (Unit) }\end{array}$ \\
\hline A & 24 & 24 & 15 \\
\hline B & 24 & 24 & 7 \\
\hline C & 24 & 12 & 15 \\
\hline D & 24 & 24 & 23 \\
\hline E & 24 & 24 & 70 \\
\hline F & 24 & 24 & 29 \\
\hline G & 24 & 24 & 56 \\
\hline H & 24 & 24 & 55 \\
\hline I & 24 & 23 & 74 \\
\hline J & 24 & 9 & 2 \\
\hline
\end{tabular}

Table 9. Storage allocation of racking items (continue).

\begin{tabular}{|c|c|c|}
\hline Rack & Amount (Unit) & Category \\
\hline A & 1902 & fast moving \\
\hline B & 9922 & fast moving \\
\hline C & 207 & fast moving \\
\hline D & 460 & slow moving \\
\hline E & 938 & slow moving \\
\hline F & 1960 & slow moving \\
\hline G & 615 & slow moving \\
\hline H & 4282 & non moving \\
\hline I & 268 & non moving \\
\hline J & 24 & non moving \\
\hline
\end{tabular}


Unracking item stored in unracking area with lenght 14,74 meters, width 14,47 meters with area wide 213,28 $\mathrm{m}^{2}$ and maximum height stack of items is 6 meters that will then be drawn up based on the category of the item closest to the unloading area is fast moving items and then a slow moving and non moving items. The result of the calculation of wide area needed for store unracking items can be seen in Table 10 .
Table 10. Wide area needed for store unracking items.

\begin{tabular}{|c|c|}
\hline Category & Wide Area Needed $\left.\mathbf{( m}^{\mathbf{2}}\right)$ \\
\hline fast moving & 86,31 \\
\hline slow moving & 34,86 \\
\hline non moving & 50,04 \\
\hline Total & $\mathbf{1 7 1 , 2 2}$ \\
\hline
\end{tabular}

The current and proposed layout design in storage one can be seen in Fig. 1.

\begin{abstract}
Warehouse 1 : New Items Size : $30,12 \mathrm{~m} \mathrm{x} \mathrm{28,911} \mathrm{m}$ Free Area 1 : bigger items placement Free Area 1 : bigger items placement

Warehouse 2 : Finance Document Size : $18,6 \mathrm{~m} \times 5,7 \mathrm{~m}$

\section{Warehouse 3 : Broke Items} Size : $18 \mathrm{~m} \times 10,8 \mathrm{~m}$

\section{Warehouse 4 : Non-Condition Items}

Size : $18 \mathrm{~m} \times 5,8 \mathrm{~m}$
\end{abstract}

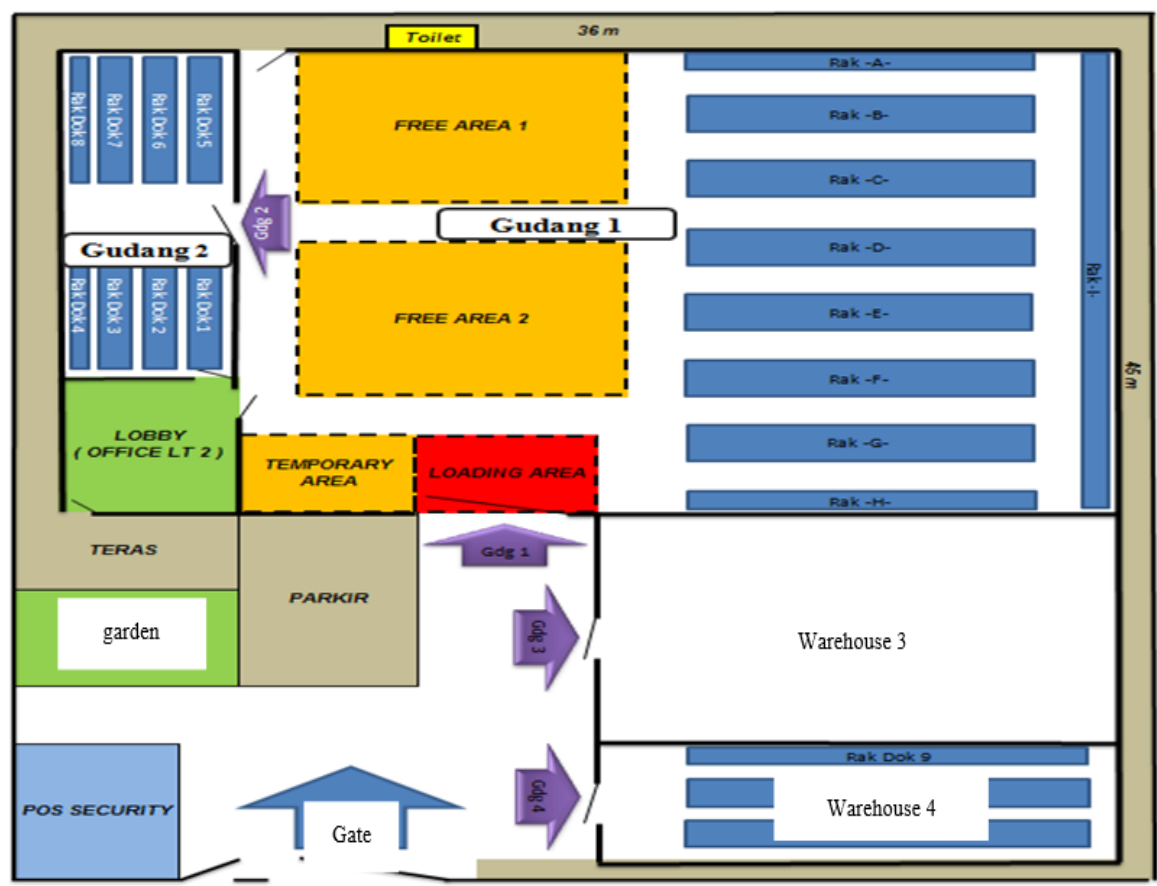

\begin{tabular}{|c|c|}
\hline \multicolumn{2}{|c|}{ LEGENDA } \\
\hline Symbol & Explanation \\
\hline & Gate \\
\hline & Door \\
\hline & Rack \\
\hline$\square$ & Fast moving items \\
\hline$\square$ & Slow moving items \\
\hline$\square$ & Non moving items \\
\hline$\square$ & Forklift \\
\hline
\end{tabular}

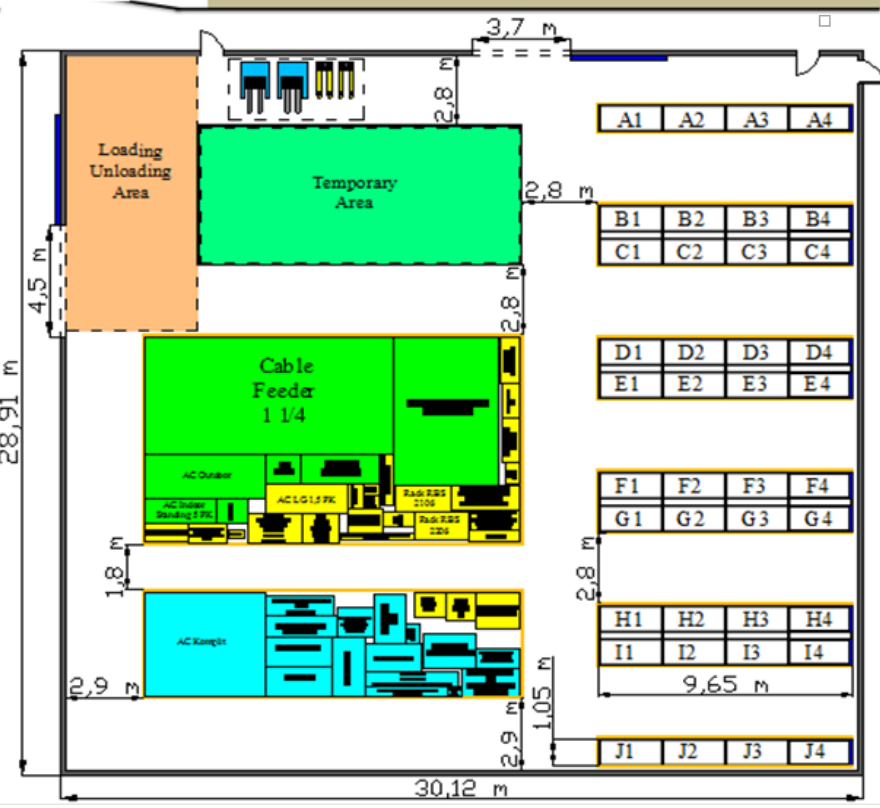

Fig. 1. Current warehouse layout and proposed layout design.

The allocation for racking items, the arrangement of each a category began from line shelves $\mathrm{A}$ as a first line rack that is the closest from the unloading area are reserved for racking items having fast moving category. The next allocation is a slow moving items that stored on the rack after the last rack of fast moving items and the last is non moving category stored after slow moving items until the rack $\mathrm{J}$ of the farthest rack from unloading area.

On the unracking items allocation of goods there are several types of items that can be stacked on top of other items to minimize the area needed to be able to save the entire unracking items. Goods storage in unracking is buildup for some types of items. The buildup is maded 
based on dimensions and type of items. larger dimensions items are set lower, and supporting extensive items stack on top of it.

The application of the concept of a dedicated storage can provide convenience to the operator with the specific location against the overall storage of items based on the level of popularity of the item stored in the Storage one.

\section{Conclusions}

From the calculation, the conclusion can be withdrawn that the number of goods is 481 types and total number is 30.236 units. From the overall racking up big items as many as 392 types, which is allocated to the Storage one only 346 types. Overall the type of items are classified into 3 category fast moving, slow moving and non-moving based on data obtained from monthly data from September 2016 until September 2017.

Racking items by categories of fast moving line use 3 rack with $\mathrm{A}, \mathrm{B}$ and $\mathrm{C}$ with the rest of the palette has not been filled in as many as 12 pallet. Slow moving category goods using 4 line the rak of the rack i.e. the D, $\mathrm{E}, \mathrm{F}$ and $\mathrm{G}$ to condition the entire pallet are used. Non moving items using 3 lines of rack i.e. the $\mathrm{H}$, I and J with the remaining pallet that has not been filled in as many as 16 pallet. There are 89 unracking items should be allocated into areas that have been determined by extensive $213.28 \mathrm{~m}^{2}$. On the categories of fast moving needs area $86.31 \mathrm{~m}^{2}$, slow moving category items requiring $34.86 \mathrm{~m}^{2}$ area and category of non moving need $50.04 \mathrm{~m}^{2}$ area so that the total area required to store whole goods unracking is $171.21 \mathrm{~m}^{2}$.

Author would like to thank Universitas Sumatera Utara for funding the financial support for publishing this paper.

\section{Refrences}

1. G. Ricahard. Warehouse Management: A Complete Guide to Improving Efficiency and Minimizing Cost in the Modern Warehouse. United Kingdom. KoganPage (2011)

2. A. Rushton, P Croucher, P Bake. The Handbook of Logistics and Distribution Management 5th Edition. United Kingdom. KoganPage. (2014)

3. R. Accorsi, G. baruffaldi, R. manzini. Picking Efficiency and Stock Safety: A Bi-Objective Storage Assignment Policy for Temperature-Sensitive Products.https://doi.org /10.1016/j.cie.2017.11.009 (2017)

4. Y. Mengfei. Enhancing Warehouse Performance by Efficient Order Picking. Shanghai, China. Eramus. (2008)

5. J. john, Bartholdi. Warehouse and Distribution Science.USA. The Supply Chain and Logistics Institute School of Industrial Engineering. (2014)

6. E. A. vildha, Wigati s. setio. Perancangan Tata Letak Gudang dengan Metode Dedicated Storage di Toko Listrik Anugrah Jaya. Seminar Nasional IENACO-2016. ISSN : 2337-4249. (2016)
7. S. Mitra, M Sukumar.R, Kumar Prince. Inventory Control Using FSN Analysis - A Case Study on a Manufacturing Industry. ISSN : 2348-7968 (2015)

8. Y. Zhang. Correlated Storage Assignment Strategy to Reduce Travel Distance in Order Picking. IFAC (International Federation of Automatic Control). 2405-8963 (2016)

9. F.guerriero, O.pisacane, F. rende. Comparing Heuristics for the Product Allocation Problem in Multi-level Warehouses Under Compatibility Constraints. (2015)

10. U. Rani V, Lin Ebi Chandra J, Jayashree D. Efficient Storage Location Assignment Using Genetic Algorithm In Warehouse Management System. 2016. ISSN : 2320-5704 (2016)

11. N. Rohan, Ghewari Asita. An Inventory Control Using ABC Analysis and FSN Analysis.ISSN : 2279-0039. (2016)

12. S, Sukaria. Metodologi Penelitian. (Graha Ilmu, Yogyakarta, 2009) 